\title{
Transition to Online Education in Schools during a SARS-CoV-2 Coronavirus (COVID-19) Pandemic in Georgia
}

\author{
Giorgi Basilaia ${ }^{1 \star}$, David Kvavadze ${ }^{1}$
}

${ }^{1}$ Business and Technology University, Tbilisi, GEORGIA

^Corresponding Author: giorgi.basilaia@btu.edu.ge

Citation: Basilaia, G., \& Kvavadze, D. (2020). Transition to Online Education in Schools during a SARS-CoV-2 Coronavirus (COVID-19) Pandemic in Georgia. Pedagogical Research, 5(4), em0060. https://doi.org/10.29333/pr/7937

\section{ARTICLE INFO}

Received: 8 Apr. 2020

Accepted: 9 Apr. 2020

\begin{abstract}
The situation in general education in Georgia has changed in the spring semester of 2020, when the first case of coronavirus COVID-19 infection was detected rising to 211 local and more than 1,5 million infection cases worldwide by the Apr. 8. 2020. Georgia became one of 188 countries worldwide that has suspended the education process.

The paper studies the capacities of the country and its population to continue the education process at the schools in the online form of distance learning, study reviews the different available platforms and indicates the ones that were used by the support of the government, such as online portal, TV School and Microsoft teams for public schools and the alternatives like Zoom, Slack and Google Meet, EduPage platform that can be used for online education and live communication and gives examples of their usage.

Authors made a case study, where the Google Meet platform was implemented for online education in a private school with 950 students, shows the usage statistics generated by the system for the first week of the online education process. Results confirm that the quick transition to the online form of education went successful and gained experience can be used in the future. The experience and studies can be useful for other countries that have not found the ways of transition yet.

The lesson learned from the pandemic of 2020 will force a generation of new laws, regulations, platforms and solutions for future cases, when the countries, government and population will be more prepared than today.
\end{abstract}

Keywords: online education, distance learning, virtual teaching, education at school, COVID-19, SARS-CoV-2, pandemic

\section{INTRODUCTION}

The general education system in Georgia is based on compulsory programs for all citizens. Children start school from the age of 6 and study at the elementary level for four years, they continue to middle school from fifth to ninth grades that are the mandatory level for everyone. From the tenth to twelfth grades are treated as secondary education. The expected years of schooling for the country is 15.4, while the mean years of schooling is 12.8 (UNDP 2019).

Main educational methodologies are:

- The traditional classroom education, where books, blackboards are used by the teacher as a teaching aid

- Modern classroom education, where the classrooms are equipped with whiteboards, projectors or audio-visual display equipment and digital boards

- Online education, where the information technologies and communications are used to help in the development and acquisition of knowledge from the different remote locations. It uses the internet and video/audio and text communication and software to create the learning environment.

There can be several types of online learning: Knowledgebase, online support, asynchronous training, synchronous training, hybrid training

Knowledgebase type is a set of lessons that are published on the website and have general instructions of learning that a student has to follow, with no support available. Online support type is a modified version of the knowledge base, where the support is available so there is a discussion board, web forum or another communication way available to get support on some topics. Asynchronous training is the one where the lessons do not take place in real-time, but the students are provided with content regularly. Instructors are assigned and provide support through email or other communication platforms. Synchronous 
training is done in real-time with a live instructor and optional moderator. There is a pre-set time to log-in to the online education environment and participants can communicate directly with the teacher and other group members. Hybrid training is a combination of online and in-person interaction.

The education system in Georgia country is based on traditional and modern classroom education and requires the pupils to attend the school classes every day.

The situation in general education in the country has changed in the spring semester of 2020, when the first case of coronavirus COVID-19 infection was detected in Georgia. A virus has infected 1,504,971 persons worldwide, by April 82020 , among these there are 211 cases in Georgia, as reported by Johns Hopkins University of medicine, Online Map. (J. H. Uni. 2020). Researchers at Imperial College in London, estimate the global impact in the year 2020 to range between 20 million deaths, with effective nonpharmaceutical interventions in place, and 40 million deaths, without such interventions (Patrick GT Walker 2020).

The learning process in Georgia was suspended from the 2 of March by the recommendation of the Ministry of Education, Science, Culture and Sport of Georgia until the March 16 (MES 2020, The official statement of the Minister), which was later has prolonged to April 1. On March 21 the country has announced a state of emergency for one month with restrictions. (The government of Georgia. 2020). Georgia became one of the 188 countries in the world that has shut down all schools or localized them in some cases to avoid the spread of the virus while affecting 1.576 million children and youth affection the $91.3 \%$ of the world's student population by April.04.2020 (Figure 1).

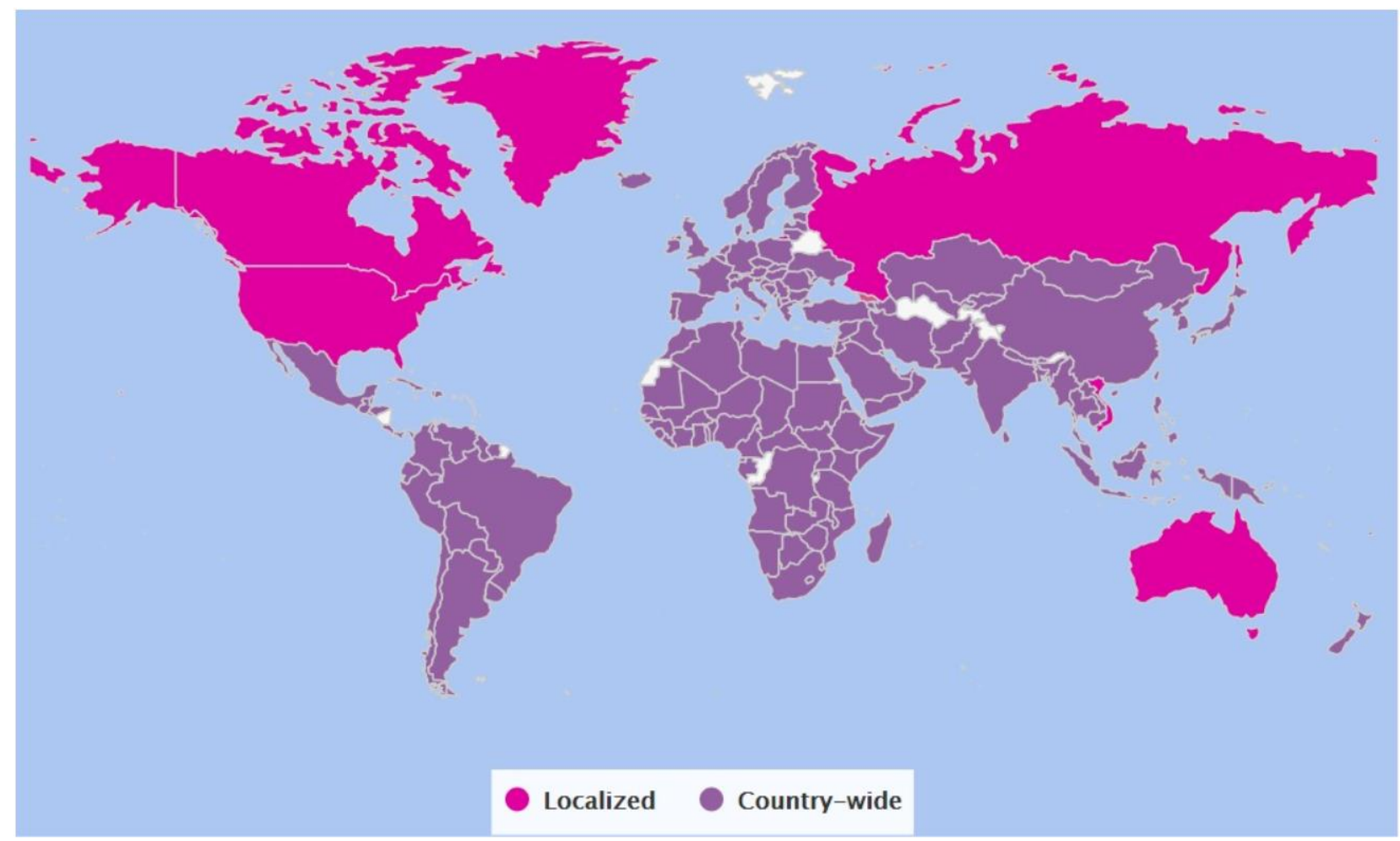

Figure 1. Countries that have shut down or localized the schools in the world (UNESCO Report)

For the year of 2020 the country has 592900 students in 2313 schools countrywide. There are 2086 public schools with 530100 and 227 private schools with 62800 students (Geostat 2020).

In a situation where the students are not allowed to go to school, the alternative is to move from traditional to online education. In this case the essential parts are the internet coverage, availability of computers or smartphones in the population. By the information of the National statistics office of Georgia for July of 2019 a total of $79.3 \%$ of the Georgian homes are connected to the internet, where the city population of 86.1 has access and the villages have $69.9 \%$. (Geostat, Share of households with internet access, 2019).

As for the computer access the country's $62.0 \%$ has the computer at home where the urban percentage is 74.6 and the rural is only $44.7 \%$ (Geostat, Share of households with computer access, 2019).

The number of the computers owned by families, especially in the rural areas of the country are lower than a $50 \%$, that can have a negative influence on the whole online education, but in some cases, the modern smartphones can be used as a substitute, if the platform of education is mobile friendly or have the mobile application available. As the Georgian National statistics office of Georgia gives information on the share of the population age 6 and older who use the mobile phone is 91.4 countrywide with 93.7\% in urban and $88.0 \%$ in rural areas (Geostat, The share of the population aged 6 and older who uses mobile phone 2019).

The Ministry of Education, Science, Culture and Sport of Georgia has made the Microsoft teams platform available for all 2086 public schools in the country. The Education Management Information System has created the accounts for all teachers 55000 teachers and 530100 students) and have built-in the virtual classrooms for all classes and relevant subjects by default. Additional online instructions were published for teachers and students to use the system (MES 2020, Ministry of Education, Science, Culture and Sport of Georgia to strengthen distance learning methods). 
Different countries worldwide have introduced various solutions during the pandemic to continue the education process. Online libraries, TV broadcasts, guidelines, resources, video lectures, online channels were introduced in at least 96 countries. To increase the coverage of the school lessons to the population, the Ministry of Education, Science, Culture and Sport of Georgia, in cooperation with Georgian Public Broadcaster's First Channel has launched the educational project titled - "Teleskola" (TV School). The live transmission of lessons is broadcasted through the TV channel in different subjects nationwide. EL.GE - a platform supported the Ministry of Education, Science, Culture, and Sport has hosted the thematic resources based on the national curriculum. (UNESCO 2020, National Learning Platforms and tools).

In this hard period, the public schools got the support from large companies such as Microsoft, Google, Zoom, and Slack are offering many of the features of their products for free:

Microsoft is offering anyone its premium version of Teams for free for six months and lifted existing user limits. Google has announced that it is offering its enterprise video conferencing features such as larger meetings up to 250 people and recording functionality for free to G Suite and G Suite for Education customers through July 1, 2020. Zoom has lifted the time limit of video calls in china, japan, Italy and the US by request. (Rani Molla, VOX. 2020).

The public schools have received large support from the government, but the private schools had to find their way to continue the education process in online. Several alternatives were discussed and used that include the communication solutions like Zoom and Google Meet.

The education management information system has reported on 24. March that the number of users in Microsoft teams was March 10 was only 750, while on 24 of March it has reached 138698 showing a significant growth in the activity. (OECD, 2020)

In the paper we will discuss the case of one private school that has transformed the education process from traditional to online in several days and discuss the results of the first week of online education. In the education process two platforms EduPage and Gsuite for education are used.

\section{RELATED LITERATURE}

Studies in the related literature demonstrate the need for readiness of countries in the cases of the pandemic in the direction of education. Although, strangely, children are found to be protected from severe or deadly critical infections, they can become the sources of spread, which was the main reason to close the schools worldwide. (Abdulamir, A. S. et al., 2020). Cakir Z et al. have provided the mathematical modeling approach that concludes, that "in the case that sufficient precautions are not taken, or precautions are reduced, the course of the pandemic may show a very fast change in the negative direction", so the social isolation has to be applied. A study by Majumder et al., indicates that contamination due to contact with the infected person is the most significant alternative of the spread of Coronavirus.

A study by Uscher-Pines et al., admits that "During an evolving influenza pandemic, community mitigation strategies, such as social distancing, can slow down virus transmission in schools and surrounding communities. To date, research on school practices to promote social distancing in primary and secondary schools has focused on prolonged school closure, with little attention paid to the identification and feasibility of other more sustainable interventions" (Uscher-Pines et al., 2018). The study concludes that information is too few for the schools to develop the social distance policies and procedures and additional research is needed.

Germann et al. discussed the opportunities to close the schools during the pandemic influenza to stop the spreading and duration of possible lockdowns before the vaccines are implemented. Faherty, L. J. et al. worked on the topic of school and its official's preparedness during a pandemic that included the physical re-arrangement of classes, limiting group works movement of students in class and creating opportunities for distance learning for missing days, but not the weeks or months as it is happening in 2020. Ash et al have supposed that distance learning can be supported by technologies such as the internet, phone, radio, TV or phone messaging, or email communication during the Flu Crisis. The interactive videoconferencing system design was proposed and implemented in elementary schools in Greece. It was found that IVC "plays a significant role in supporting collaborative synchronous learning activities at a distance" (Anastasiades et al., 2010). The study of Muirhead, W. (2000), admits that online education is new in schools and can be considered for enhancing traditional schools and home-schooling. Qi, W. has made a case study on collaborative environment for distance teaching and learning and reviewed existing platforms as well and Baiyere et al. has made a project enabling and facilitating collaborative teaching in information systems and found that virtual environment should be suitable for other courses as well. Another study was done on a case of English language teaching and learning using the virtual distance learning environment and came to the result that Virtual environments allow students to create a world that encompasses anything they can dream up. Interaction, simulation, and collaboration enable learning in the interactive environment (Mnyanyi et al., 2009; Thamarana, S., 2016).

Some studies state that prolonged school closures and home confinement might have the negative effects on children's physical and mental health (Brazendale, $\mathrm{K}$ et al., 2017). The "psychological impact of quarantine is wide-ranging, substantial and can be long-lasting" (Brooks S. et al., 2020).

Different studies have shown that although there are some examples of having a plan of using the distance/online learning during the pandemic, they are mostly concentrated on small cases and not a global crisis as it is happening in COVID-19 pandemic of 2020. Especially the countries that are having the limited technologies have problems in schools are not ready for the complete implementation of the countrywide online education (Sintema J, 2020). Results of different studies shows that the virtual teaching 
environments can be successfully used in school or higher education in case of having appropriate technical environment and support.

\section{RELATED WORKS}

The education system at schools is straighter forward, then the system in the universities where the students have lots of different courses at different days and periods. When suggesting the university online transformation, the different courses have to arrange the meetings so the different students join them for different subjects. Basilaia G, et al. (2020) The situation with general education, especially in the case of schools is different. The school students have a daily fixed schedule of classes. They also mostly remain in their classrooms and different subject teachers enter a class on each hour.

Selected public schools have entered a pilot project to have the central "electronic journal portal" eSchool, where the grades can be entered by teachers in the database from the school territory, but the private schools are not eligible to use this system.

One alternative for the school management digital system is aSc Edupage, the system that is used in 173 countries, at 150000 schools. The system is cloud-based unity of web portal and mobile application, and has most of the functions that are suitable a general education process management at schools with the basic free functionality. The system has the functionality of timetable automation, curriculum, attendance control, homework assigning, grading and messaging features. Parents can be part of the process where they can get the information about grades and results, attendance and communicate with teachers through the system. (Edupage. 2020).

The system has a large list of interesting functions such as:

- Mobile application

- Timetable

- Powerful automatic generator

- Substitution

- Share timetable and substitution

- Full webpage

- Class register

- Teaching plans

- Lesson preparations

- Powerful e-learning tool

- Interactive lessons

- The results

- Grades

- Attendance tracking

- Absence Notes

- Access control

- Payments

- School canteen software

- Homework

- Competency-based evaluation

- Track students' progress

- Behavior and notices

- Certificates generating

- Report designer

- Calendar

- Room or event booking

- Registration

- Parent-Teacher meetings

- Admissions

- Organize surveys and collect results

- Achievements and awards

The above-listed functions are great, but the main lack of the system is the absence of the video/audio conferencing tools for online education. 
We have found an easy way to use Google's G Suite for education to make an addition to the existing school management system for videoconferencing. In the process of transition to the online experience of the team, when replacing the classical teaching form with the online at the university was essential.

It was realized that a school that used $\mathrm{G}$ suite for education, could use the platform and tools available for the online teaching process as an addition. By march of 3, Google has announced that it is extending the Hangouts Meet premium features to all $G$ Suite customers, (Google 2020). In addition to the standard features, the Google has made changes to the Hangouts Meet to make it closer for remote learning and more robust for the school implementation. Google (2020. Hangouts Meet improvements for remote learning March). In particular, the important changes were:

- The only meeting creators and calendar owners can mute or remove other participants in a meeting.

- Meeting participants will not be able to re-join nicknamed meetings once the final participant has left.

Each of the school classes is assigned a number, corresponding to the grade and a letter, corresponding to the group (for example $1 \mathrm{a}$ or $12 \mathrm{~b}$ ). We had to be sure that the timetable for the students will not change too much from the existing one that they had before pandemic started. Additionally, the structure of the lessons had to remain as before - meaning that the students stay in classes and different subject teachers arrive at a class for a designated subject. To maintain the structure an email account was created for each class (Class numbers are created for each available class at the term). A separate room was created for teachers to meet between classes and discuss the actual topics as they did in real-life before (Table 1).

Table 1. General structure of created email accounts and generated virtual classroom links

\begin{tabular}{cccc}
\hline Class name & Class Teacher (owner) & Email & Link to the virtual classroom \\
\hline $1 \mathrm{~A}$ & Teacher 1 & 1a@pschool.edu.ge & https://meet.google.com/roomlink1a \\
\hline 2A & Teacher 2 & 2a@pschool.edu.ge & https://meet.google.com/roomlink2a \\
\hline 3A & Teacher 3 & 3a@pschool.edu.ge & https://meet.google.com/roomlink3a \\
\hline 4A & Teacher 4 & 4a@pschool.edu.ge & https://meet.google.com/roomlink4a \\
\hline $5 \mathrm{~A}$ & Teacher 5 & 5a@pschool.edu.ge & https://meet.google.com/roomlink5a \\
\hline $6 \mathrm{~A}$ & Teacher 6 & 6a@pschool.edu.ge & https://meet.google.com/roomlink6a \\
\hline 7A & Teacher 7 & 7a@pschool.edu.ge & https://meet.google.com/roomlink7a \\
\hline 8A & Teacher 8 & 8a@pschool.edu.ge & https://meet.google.com/roomlink8a \\
\hline 9A & Teacher 9 & 9a@pschool.edu.ge & https://meet.google.com/roomlink9a \\
\hline $10 \mathrm{~A}$ & Teacher 10 & 10a@pschool.edu.ge & https://meet.google.com/roomlink10a \\
\hline $11 \mathrm{~A}$ & Teacher 11 & 11a@pschool.edu.ge & https://meet.google.com/roomlink11a \\
\hline hA & Teacher 12 & 12a@pschool.edu.ge & https://meet.google.com/roomlink12a \\
\hline Teachers' lounge & - & lounge@pschool.edu.ge & \\
\hline
\end{tabular}

An online form was created to make an every-day assessment of the online learning process and analyze how successful was the transformation to online learning. The form had to be filled by the teacher at the end of each class meeting where besides the writing the number of attendees, the technical side of the class meeting had to be evaluated where the quality of video/voice/presentation is estimated for 4 points (3 - perfect, 2 - good, 1 - poor, 0 - failed) and the process of the teaching also had to be evaluated where the student's behavior is evaluated during online classes, meaning how organized they were in attending the class (Table 2).

Table 2. Example of online teaching evaluation form

\begin{tabular}{cccccc}
\hline Class name & Subject & Teacher & Number of attended students & Technical (3) & Process (3) \\
\hline \multirow{3}{*}{$\mathbf{1 A}$} & Georgian language & Teacher 1 & 20 & 2 \\
\cline { 2 - 5 } & Nature & Teacher 2 & 19 & 2 \\
\cline { 2 - 5 } & Engthematics & Teacher 3 & 21 & 2 & 2 \\
\cline { 2 - 5 } & Arts & Teacher 4 & 20 & 2 \\
\hline
\end{tabular}

To assign a permanent link to the classroom the repetitive daily google calendar event was created for a duration of 5 hours that lasts for 3 months (Figure 2). This method ensures that the permanent link is assigned to the event that in our case is the classroom link.

As a result, a structured virtual environment was created, where the teachers can enter the classrooms at their designated timetable as if they were doing that commonly. Each generated classroom link was sent to the parent/student via an internal learning management system. In such a structure, the student has to use one link to enter the virtual class and wait for a teacher and other students to join. 


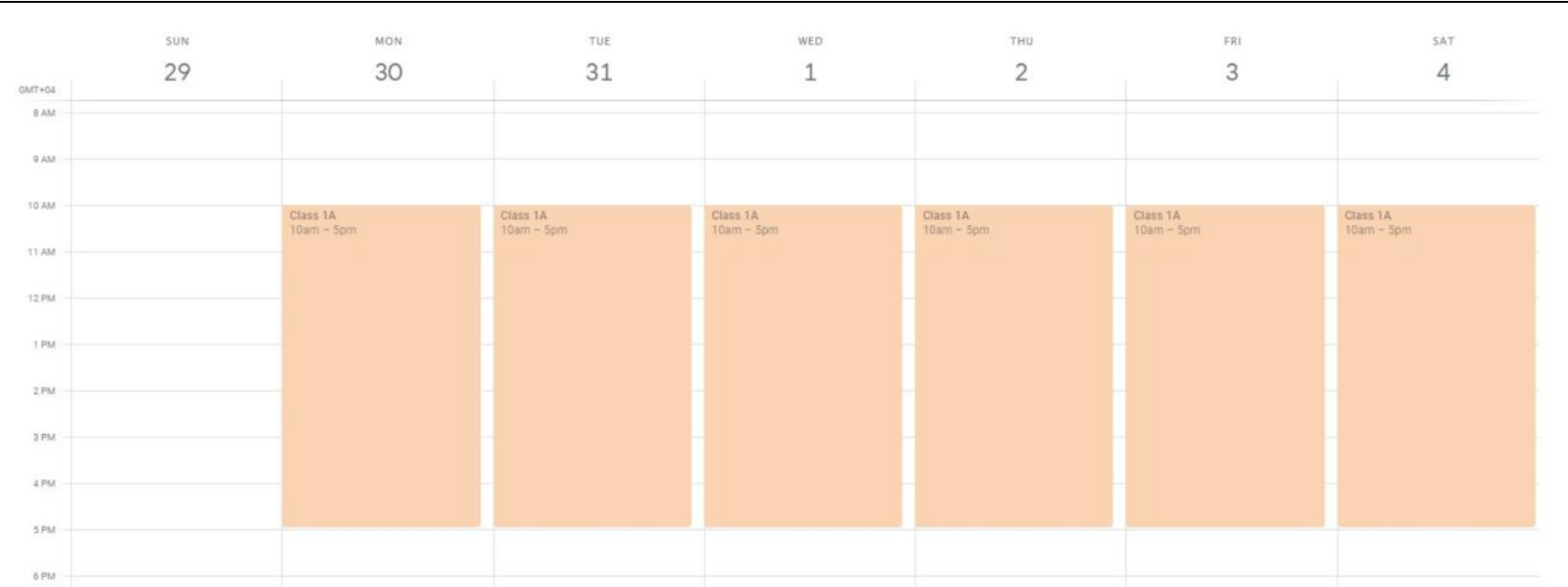

Figure 2. Google Calendar events for the first week of online learning

\section{RESULTS AND DISCUSSION}

During the first week of the online teaching in a private school with 920 students, where online learning was introduced 47 virtual classrooms and a virtual teacher's lobby were created using the above-described structure. 86 Teachers were trained online in using the Google Hangouts Meet tools and get familiar with the created structure.

The classroom links were sent to the students and the parents through the EduPage system. The list was shared among the school teachers, so each teacher could join a class based on the available timetable.

The Google Meet quality tool was used to extract the additional statistics of the meetings from the system's admin panel for the period of the first week of the online education.

Total communication device usage was calculated based on the total number of student connections and separately by their unique names Table 3.

Table 3. Device/platform and OS usage of students for 1st week of education period

\begin{tabular}{ccccc}
\hline Type of Used Platform & Web/PC/Laptop & Mobile/Tablet & iOS & Android \\
\hline By total number of connections & $54.71 \%$ & $45.29 \%$ & $26.8 \%$ & $18.52 \%$ \\
\hline By Unique Names of students & $44.84 \%$ & $55.16 \%$ & $33.79 \%$ & $21.37 \%$ \\
\hline
\end{tabular}

Desktop screen sharing was intensively used by the teachers for the presentation of materials, resulting in a total of 78 hours of screen sharing for one week of lessons. The total time of 513 hours of video has been broadcasted, which is on average 11 hours of video per class and 605 hours of audio stream have been transmitted resulting in 12.87 Hours per class. About 5 hours total time was spent without video/audio transmission that can be a waiting time until the lesson is started (Table 4).

Table 4. Usage of online meeting tools for 1st week of education period

\begin{tabular}{ccc}
\hline Activity & Time (hours) & Average per class (Hours) \\
\hline Desktop screen sharing & 78 & 1.66 \\
\hline Video Broadcasting & 513 & 10.91 \\
\hline Audio Streaming & 605 & 12.87 \\
\hline Meeting with no video/audio & 5 & 0.1
\end{tabular}

In the regular, non-pandemic situation the common times are 35 minutes for the first-grade students and 45 minutes for the II-XII grades. In case, when the online teaching has started, changes in the duration of the online lessons were done to avoid the prolonged contact of the students with a computer, the duration of the classes was minimized to 30 minutes for all of the grades. In some cases, the teacher is allowed to add additional 10-15 minutes if there was a technical problem or the students were working on an assignment. Additionally, to give the students a larger break between, the lesson schedule has been adjusted, so each lesson starts on fixed hours.

The number of lessons had been decreased, so I-II term students have 2-3 lessons a day, III-VII term students have 3-4 lessons, VIII-XII term students have 4-5 lessons a day. To recover the 2 weeks of prolonged spring holidays, the lessons can be appointed on Saturdays.

Attendance on the online virtual classes are the following: I-VII and XII grades have $98 \%$ attendance, VIII-XI grades have $94 \%$.

During the first week of the online teaching none of the lessons have failed or been canceled. Very few (Total 10 cases) percent of the teachers had technical issues in the first week, and the appeared problems were connected to the personal computer video/voice configuration or misusage of the functions.

The study has some limitations in case of home assignments, as the statistics report shows that the lower grade students are doing assignments better than the higher grades, but this might be resulted by the recommendation from the ministry of education, science, culture and sport of Georgia to temporary cancel the official grading for the students during the online education process. The data of only one private school was processed only for the first week, we do not have the data from other 
schools or the ministry to assess all other private or public schools. The process of estimation needs time, the information provided is of the first week period and we can not predict how will students behave during other weeks of the pandemic, when the additional factors exist.

\section{CONCLUSION AND RECOMMENDATIONS}

Based on the first-week statistics of the online teaching process at one of the private schools in Georgia, we can conclude that transition from the traditional to the online education systems at the school was successful.

The system and the skills that were gained by the teachers, students and school administration can be used in the postpandemic period, in case of missing lessons or other similar special cases like the current one. The teachers have re-realized the distance learning in a new way, have adapted the assignments to the new format of the lessons, that will be positively reflected on their qualification. The online education format can be useful in the post-pandemic period, especially in the case of students with special needs.

Additional hours will be used for the individually checking the assignments and returning the feedbacks, that is one of the ways to increase effectiveness in the group teaching. Students will work more independently which is the advantage of getting new skills.

The lesson learned from the pandemic of 2020 will force a generation of new laws, regulations, platforms and solutions for future cases, when the countries, government and population will be more prepared than today.

The study is important for the future because it shows the case of a country that has used the available free tools to transit the traditional school lessons to the online education during the pandemic. Online learning needs to re-arrange the exams and home assignments to the open book principle that is not developed and popular for now. Preparing new kinds of such assignments in all subjects will need additional work. The problem of grading is actual when the students stay outside of the school and new technologies have to be considered for anti-plagiarism and avoiding cheating.

The quality of the learning online needs future study. Currently there was no time to get into details of quality assurance of the online teaching method as the main goal was to save the education process and continue it in any possible format. The statistics that are given in the paper are measured for the first week of the online teaching process are important to be compared to the other weeks and total semester. Also, if the information on grades can be available it can be compared to previous face-to-face classes and next year classes to get the comparative results. The teaching methodologies have to be studied and improved, including the available tools and platforms. We suggest that the google meet system to be integrated to the google classroom platform, or the separate platform needs to be created for education purposes that might include the laboratory practice simulators for schools in STEM courses.

When changing to online education, the country needs to estimate how successful was the process for the whole country or the world. As our paper covers the one private school, other schools need to be assessed to get the total results for the spring 2020 semester.

\section{REFERENCES}

Abdulamir, A. S., \& Hafidh, R. R. (2020). 'The Possible Immunological Pathways for the Variable Immunopathogenesis of COVID19 Infections among Healthy Adults, Elderly and Children'. Electronic Journal of General Medicine, 17(4), em202. https://doi.org/10.29333/ejgm/7850

Archambault, L. and Crippen, K. (2009) 'K-12 distance educators at work: Who's teaching online across the united states', Journal of Research on Technology in Education, 41(4), 363-391. https://doi.org/10.1080/15391523.2009.10782535

Anastasiades, P. S. et al. (2010) 'Interactive Videoconferencing for collaborative learning at a distance in the school of 21st century: A case study in elementary schools in Greece', Computers and Education, 54(2), $321-339$. https://doi.org/10.1016/j.compedu.2009.08.016

Ash K. (2014) 'E-Learning's Potential Scrutinized in Flu Crisis'. Education Week, 282009, 1-13.

Baiyere, A., \& Li, H. (2016) 'Application of a virtual collaborative environment in a teaching case'. In AMCIS 2016: Surfing the IT Innovation Wave - 22nd Americas Conference on Information Systems.

Basilaia, G., et al. (2020) 'Replacing the Classic Learning Form at Universities as an Immediate Response to the COVID-19 Virus Infection in Georgia', International Journal for Research in Applied Science \& Engineering Technology (IJRASET), 8(III), $101-108$. https://doi.org/10.22214/ijraset.2020.3021

Brazendale, K., et al. (2017) 'Understanding differences between summer vs. school obesogenic behaviors of children: The structured days hypothesis', International Journal of Behavioral Nutrition and Physical Activity, 14. https://doi.org/10.1186/s12966-017-0555-2

Brooks, S. K., Webster, R. K., Smith, L. E., Woodland, L., Wessely, S., Greenberg, N., \& Rubin, G.J., 2020. The psychological impact of quarantine and how to reduce it: rapid review of the evidence. The Lancet. https://doi.org/10.1016/S0140-6736(20)30460-8

Cakir, Z., \& Savas, H. B. (2020). A Mathematical Modelling Approach in the Spread of the Novel 2019 Coronavirus SARS-CoV-2 (COVID-19) Pandemic. Electronic Journal of General Medicine, 17(4), em205. https://doi.org/10.29333/ejgm/7861 
EDUPAGE. (2020). EduPage,'EduPage features'. Retrieved on 5 April 2020 from https://www.edupage.org/

Faherty, L. J., et al. (2019) 'School and preparedness officials' perspectives on social distancing practices to reduce influenza transmission during a pandemic: Considerations to guide future work'. Preventive Medicine Reports, 14(December 2018), 100871. https://doi.org/10.1016/j.pmedr.2019.100871

Geostat. (2020). 'Number of General Education Schools and Pupils in them', National statistics office of Georgia. Retrieved on 2 April 2020 from https://www.geostat.ge/en/modules/categories/59/general-education

Geostat. (2019). 'Share of households with internet access', National statistics office of Georgia. Retrieved on 1 April 2020 from https://www.geostat.ge/en/modules/categories/106/information-and-communication-technologies-usage-in-households

Geostat. (2019). 'Share of households with computer access, National statistics office of Georgia'. Retrieved on 1 April 2020 from https://www.geostat.ge/en/modules/categories/106/information-and-communication-technologies-usage-in-households

Geostat. (2019). 'Share of population aged 6 and older who uses mobile phone'. National statistics office of Georgia. Retrieved on 1 April 2020 from https://www.geostat.ge/en/modules/categories/106/information-and-communication-technologies-usagein-households

Germann, T. C., et al. (2019). 'School dismissal as a pandemic influenza response: When, where and for how long?', Epidemics, 28(June), 100348. https://doi.org/10.1016/j.epidem.2019.100348

Google (2020). 'Extending Hangouts Meet premium features to all G Suite customers through July 1', 2020. Retrieved on 6 April 2020 from https://gsuiteupdates.googleblog.com/2020/03/enabling-hangouts-meet-premium-features.html

Google (2020). 'Hangouts Meet improvements for remote learning March 19, 2020'. Retrieved on 6 April 2020 from https://gsuiteupdates.googleblog.com/2020/03/hangouts-meet-edu-updates.html

J. H. University. (2020). Johns Hopkins University. 'Coronavirus Resource Center'. Retrieved on 6 April 2020 from https://coronavirus.jhu.edu/map.html

Majumder, P., Biswas, P., \& Majumder, S. (2020). Application of New TOPSIS Approach to Identify the Most Significant Risk Factor and Continuous Monitoring of Death of COVID-19. Electronic Journal of General Medicine, 17(6), em234. https://doi.org/10.29333/ejgm/7904

MES. (2020). 'The official statement of the Minister of Education, Science, Culture and Sport, Mikheil Chkhenkeli'. Retrieved on 1 April 2020 from https://www.mes.gov.ge/content.php?id=10165\&lang=eng

MES. (2020). Ministry of Education, Science, Culture and Sport of Georgia. 'Ministry of Education, Science, Culture and Sport of Georgia to strengthen distance learning methods'. Retrieved on 2 April 2020 from https://www.mes.gov.ge/content.php?id=10271\&lang=eng

Mnyanyi, C. B. F., \& Mbwette, T. S. A. (2009) 'Open and Distance Learning in Developing Countries: The Past, The Present and The Future', Open University of Tanzania: Dares salaam. Retrieved from http://citeseerx.ist.psu.edu/viewdoc/summary? doi=10.1.1.567.7197

Moore, J. L., Dickson-Deane, C., \& Galyen, K. (2011) 'E-Learning, online learning, and distance learning environments: Are they the same?', Internet and Higher Education. https://doi.org/10.1016/j.iheduc.2010.10.001

Muirhead, W. (2000), 'Online education in schools', International Journal of Educational Management, 14(7), 315-324. https://doi.org/10.1108/09513540010378969

OECD. (2020). 'A framework to guide an education response to the COVID-19 Pandemic of 2020'. Retrieved on 4 April 2020 from https://read.oecd-ilibrary.org/view/?ref=126_126988-t63lxosohs\&title=A-framework-to-guide-an-education-response-tothe-Covid-19-Pandemic-of-2020

Walker, P. G. T, Whittaker, C., Watson, O., et al. (2020). 'The Global Impact of COVID-19 and Strategies for Mitigation and Suppression'. Imperial College London. https://doi.org/10.25561/77735

Qi, W. (2017) 'Evaluating a virtual collaborative environment for interactive distance teaching and learning: A case study'. Smart Innovation, Systems and Technologies, 11-18. https://doi.org/10.1007/978-3-319-50212-0_2

Rani Molla, VOX (2020). 'Microsoft, Google, and Zoom are trying to keep up with demand for their now free work-from-home software'. Retrieved on 4 April 2020 from https://www.vox.com/recode/2020/3/11/21173449/microsoft-google-zoom-slack-increaseddemand-free-work-from-home-software

Sintema, E. J. (2020). Effect of COVID-19 on the Performance of Grade 12 Students: Implications for STEM Education. Eurasia Journal of Mathematics, Science and Technology Education, 16(7), em1851. https://doi.org/10.29333/ejmste/7893

Thamarana, S. (2016). 'Role of E-learning and Virtual Learning Environment in English language learning Role of E-learning and Virtual Learning Environment in English'. Research Scholar, 1(August), 1-8. https://doi.org/10.13140/RG.2.1.4665.1122

The Government of Georgia. (2020). 'List of Actions Restricted and Permitted under the Government Resolution during the State of Emergency Enforced on the Territory of Georgia'. Retrieved on 1 April 2020 from http://gov.ge/index.php?lang_id=ENG\&sec_id=288\&info_id=75732

UNDP. (2019). 'Human Development Index and its components.' New York: United Nations Development Programme. Retrieved on 4 April 2020 from http://hdr.undp.org/en/content/table-1-human-development-index-and-its-components\#a

UNESCO. (2020). UNESCO Report, 'COVID-19 Educational Disruption and Response'. Retrieved from https://en.unesco.org/covid19/educationresponse/ 
UNESCO. (2020). UNESCO Report, 'National learning platforms and tools'. Retrieved on 4 April 2020 from https://en.unesco.org/covid19/educationresponse/nationalresponses

Uscher-Pines, L., et al. (2018) 'School practices to promote social distancing in K-12 schools: Review of influenza pandemic policies and practices'. BMC Public Health. BMC Public Health, 18(1), pp. 1-13. https://doi.org/10.1186/s12889-018-5302-3 